Full Paper

\title{
Solid State Electrochemical Oxidation Mechanisms Of Morin in Aqueous Media
}

\author{
Patricia Janeiro, Ana Maria Oliveira Brett* \\ Departamento de Química, Faculdade de Ciências e Tecnologia, Universidade de Coimbra, 3004-535 Coimbra, Portugal \\ *e-mail: brett@ci.uc.pt
}

Received: July 1, 2004

Final version: September 13, 2004

\begin{abstract}
The mechanism of electrochemical oxidation of morin has been studied using cyclic, differential pulse and squarewave voltammetry techniques in aqueous electrolyte with solid, insoluble morin hydrate mechanically transferred to a glassy carbon electrode surface, over a wide $\mathrm{pH}$ range. The oxidation mechanism proceeds in sequential steps, related with the hydroxyl groups in the three aromatic rings and the oxidation is $\mathrm{pH}$ dependent over part of the $\mathrm{pH}$ range the oxidation potentials are shifted to lower values with increasing $\mathrm{pH}$. Oxidation of the $2^{\prime}, 4^{\prime}$ dihydroxy moiety at the $\mathrm{B}$ ring of morin occurs first, at very low positive potentials, and is a one electron one proton reversible reaction. The hydroxyl groups oxidized at more positive potentials were shown to undergo an irreversible oxidation reaction.
\end{abstract}

Keywords: Morin, Oxidation mechanism, Radical scavenging activity, pH dependent antioxidant activity, Polyphenols, Flavonoids, Free radicals

\section{Introduction}

Polyphenols, flavonoids, and tannins are widely distributed in plants, mainly in fruits and vegetables, contributing to their flavor and color [1]. The flavonoids constitute a large class of compounds containing a number of phenolic hydroxyl groups attached to ring structures, conferring antioxidant activity [2-5]. It has been shown that the antioxidant activity of flavonoids is due to the aromatic $\mathrm{OH}$ groups [6]. The structural groups undergoing electron transfer reactions in the flavonoids are 1) the pyrogallol group; 2) the catechol group; 3) the 2,3-double bond in conjugation with a 4-oxo group and a 3-hydroxyl group and 4) additional resonance-effective substituents [7].

Electrochemical measurements leading to the determination of physicochemical parameters for antioxidants (e.g., redox potential, number of electrons transferred, electrodereaction rate constant, etc), are very relevant not only for evaluating the antioxidative abilities of flavonoids [8] but also for understanding their reaction mechanisms.

The half-wave potential $\left(E_{1 / 2}\right)$ is a useful parameter for supplying information on the scavenging activity of the flavonoids. This has been rationalized on the basis that both electrochemical oxidation and hydrogen-donating free radical scavenging involve the breaking of the same phenolic bond between oxygen and hydrogen, producing the phenoxy radical and hydrogen, in an electron and proton transfer reaction. Thus a flavonoid which has a low value of $E_{1 / 2}$ is a good scavenger [1].

In contrast to the large number of solution-phase investigations, there have been few studies within $\mathrm{H}$ bonded solid-state materials. The study of solid-state materials offers significant advantages, since forces such as intermolecular $\mathrm{H}$-bonding are necessarily weak in solution [9].

The voltammetry of microparticles (VMP), a methodology based on the mechanical immobilization of solid particles at the surface of carbon or metal electrodes in the absence of binders, widens the possibilities of solid-state electroanalysis due to its broad applicability. The special case, when the solid compounds are dissolved during the electrochemical reactions, has formerly been called abrasive stripping voltammetry (AbrSV). Virtually any solid phase containing redox centres can yield a characteristic voltammetric signal [10]. The VMP method is attractive also due to the ease of preparation of the solid sample and the short time scale required for an electrochemical measurement. Additionally, the technique allows real-time monitoring of reactions by in situ spectroelectrochemical methods. VMP has become an important step towards direct analysis of well defined solid powders without their further pretreatment or time-consuming deposition procedures [11]. This technique, however, presents a disadvantage: unknown total amount of deposited solid.

The mechanical attachment of compounds at solid electrode surface was introduced by Scholz et al. [12] and has been used to study the electrochemistry of a wide variety of solid compounds. Several electrochemical solid systems have already been studied to compare VMP and other procedures. For example, the general behavior of Prussian Blue (iron hexacyanoferrate) is very similar when it is studied with carbon paste electroactive electrode (CPEE), VMP, and a thin film electrode [13]. Similarly, there is good agreement between redox cycling of $\mathrm{MnO}_{2}$ using VMP and the compact-electrode method [14], but the VMP measurement is ten to a hundred times faster. In the voltammetry of 
<smiles></smiles>

Scheme 1. Structure of morin hydrate.

organic microparticles, redox reactions can be either destructive, i.e., leading to a dissolution of the particle, or not, depending on the solubility of the reaction products [15]. The heterogeneous charge transfer reaction occurs at the three-phase boundary, at which the electrode, the particle and the electrolyte are in contact [16-18].

The mechanism of oxidation of phenols is of interest particularly in connection with biosynthetic-type oxidative coupling reactions. Oxidation can occur either in a single one-electron, single two-electron or in two one-electron steps. In the course of investigation of the mechanisms of electrooxidation it has been demonstrated that a systematic study of the dependence of the voltammetric peak potentials and peak currents with $\mathrm{pH}$ enabled their elucidation [19].

Morin $\left(2^{\prime}, 3,4^{\prime}, 5,7\right.$-pentahydroxyflavone) is a bioactive flavonoid found in yellow Brazil wood (Scheme 1). It is one of the antioxidants that can protect various human cells, such as myocytes, endothelial cells, and hepatocytes against oxyradicals generated in situ. Studies undertaken imply that morin may protect the cardiovascular tissues of cancer patients from free-radical-mediated damage when doxorubicin or mitomycin $\mathrm{C}$ are used in chemotherapy [20]. The antioxidant activity of quercetin is almost twice morin's antioxidant activity which indicates the importance of the adjacent two hydroxyl groups in the ortho-diphenolic arrangement in the ring-B of hydroxyflavones [5, 21].

Electrochemical studies revealed general trends in the electron-donating abilities of flavonoids [22]. The reduction potentials of flavonoids depend strongly on the electron donating properties of the substituents in the ring B [23], and on the ring $\mathrm{B}$, the most oxidizable phenolic group is the more basic site [22]. The $\mathrm{p} K_{\mathrm{a}}$ values were assigned to ring $\mathrm{A}$ and ring $\mathrm{B}$ following reference [24]. The mechanism of phenolic compound action as antioxidants seems to involve the ability of phenols to scavenge radicals by an $\mathrm{H}$-atom or electron transfer process by which the phenol is converted into a phenoxyl radical. The ease of oxidation of the phenol is of importance for its effectiveness as an antioxidant [25].

In this study, the electrochemical mechanism of oxidation of morin hydrate was investigated, for a wide range of solution conditions, using cyclic, differential pulse and square-wave voltammetry. Information on the mechanism of morin oxidation obtained from results at different $\mathrm{pHs}$ may play a crucial role in understanding its antioxidant activity.
Table 1. Supporting electrolyte buffer solutions.

\begin{tabular}{lll}
\hline Solution 1 & Solution 2 & $\mathrm{pH}$ \\
\hline $0.2 \mathrm{M} \mathrm{KCl}$ & $0.2 \mathrm{M} \mathrm{HCl}$ & 1.1 \\
$0.2 \mathrm{M} \mathrm{KCl}$ & $0.2 \mathrm{M} \mathrm{HCl}$ & 2.1 \\
$0.2 \mathrm{M} \mathrm{NaOAc}$ & $0.2 \mathrm{M} \mathrm{HOAc}$ & 3.2 \\
$1.0 \mathrm{M} \mathrm{NaOAc}$ & $1 \mathrm{M} \mathrm{HOAc}$ & 4.5 \\
$0.2 \mathrm{M} \mathrm{NaOAc}^{2} \mathrm{M} \mathrm{Na}_{2} \mathrm{HPO}_{4}$ & $0.2 \mathrm{M} \mathrm{HOAc}_{4}$ & 5.2 \\
$0.2 \mathrm{M} \mathrm{Na}_{2} \mathrm{HPO}_{4}$ & $0.2 \mathrm{M} \mathrm{NaH}_{2} \mathrm{PO}_{4}$ & 6.0 \\
$0.2 \mathrm{M} \mathrm{Na}_{2} \mathrm{HPO}_{4}$ & $0.2 \mathrm{M} \mathrm{NaH}_{2} \mathrm{PO}_{4}$ & 7.0 \\
$0.025 \mathrm{M} \mathrm{Na}_{2} \mathrm{~B}_{4} \mathrm{O}_{7} .10 \mathrm{H}_{2} \mathrm{O}$ & $0.2 \mathrm{M} \mathrm{NaH}_{2} \mathrm{PO}_{4}$ & 8.0 \\
$0.2 \mathrm{M} \mathrm{KCl}$ & $0.1 \mathrm{M} \mathrm{NaOH}$ & 9.4 \\
$0.2 \mathrm{M} \mathrm{KCl}$ & $0.2 \mathrm{M} \mathrm{NaOH}$ & 12.0 \\
\hline
\end{tabular}

\section{Experimental}

Morin hydrate $\left(2^{\prime}, 3,4^{\prime}, 5,7\right.$-pentahydroxyflavone) of $95 \%$ purity was from Sigma-Aldrich, Madrid, Spain, and all the other reagents were Merck analytical grade. All solutions were made up using ultrapure water obtained from a Millipore Milli-Q purification system (resistivity =18 M $\Omega$ $\mathrm{cm}$ ). All experiments were carried out at room temperature (ca. $22 \pm 1^{\circ} \mathrm{C}$ ) and in the presence of dissolved oxygen. Solutions of buffer supporting electrolyte of ionic strength $0.2 \mathrm{M}$ were used in all experiments, Table 1.

The $\mathrm{pH}$ measurements were carried out with a CRISON GLP 21 pH-meter.

Electrochemical experiments were carried out using an Autolab PGSTAT 10 running with GPES (General Purpose Electrochemical System) version 4.9, Eco-Chemie, Utrecht, The Netherlands. Voltammetric curves were recorded at room temperature using a three-electrode system in a small volume electrochemical cell of capacity $2 \mathrm{~mL}$ (Cypress System, Inc., USA). The working electrode was a glassy carbon mini-electrode of $1.5 \mathrm{~mm}$ diameter; $\mathrm{Ag} / \mathrm{AgCl}$ (saturated $\mathrm{KCl}$ ) was used as a reference electrode and platinum wire as a counter electrode. In this work, all potentials were reported vs. $\mathrm{Ag} / \mathrm{AgCl}$ (sat $\mathrm{KCl}$ ) electrode.

The electrochemistry of this compound was performed with the solid compound attached by mechanical pressing on the glassy carbon electrode (GCE).

After the measurement, the glassy carbon electrode was cleaned by polishing with diamond spray (6 and $1 \mu \mathrm{m})$. Cyclic voltammograms were performed at scan rates of 25 , 50,100 and $200 \mathrm{mV} \mathrm{s}^{-1}$. Differential pulse voltammetry conditions used were pulse amplitude $50 \mathrm{mV}$, pulse width 70 $\mathrm{ms}$ and scan rate of $5 \mathrm{mV} \mathrm{s}{ }^{-1}$. Square-wave voltammetry conditions were frequencies of 13,25 and $50 \mathrm{~Hz}$, amplitude $50 \mathrm{mV}$, and potential increment $2 \mathrm{mV}$ (effective scan rate 25 , 50 and $100 \mathrm{mV} \mathrm{s}^{-1}$, respectively).

\section{Results and Discussion}

It has been shown that the antioxidant activity of flavonoids resides in the aromatic $\mathrm{OH}$ groups [21]. The morin molecule presents 5 functional $\mathrm{OH}$ groups attached to ring structures, 


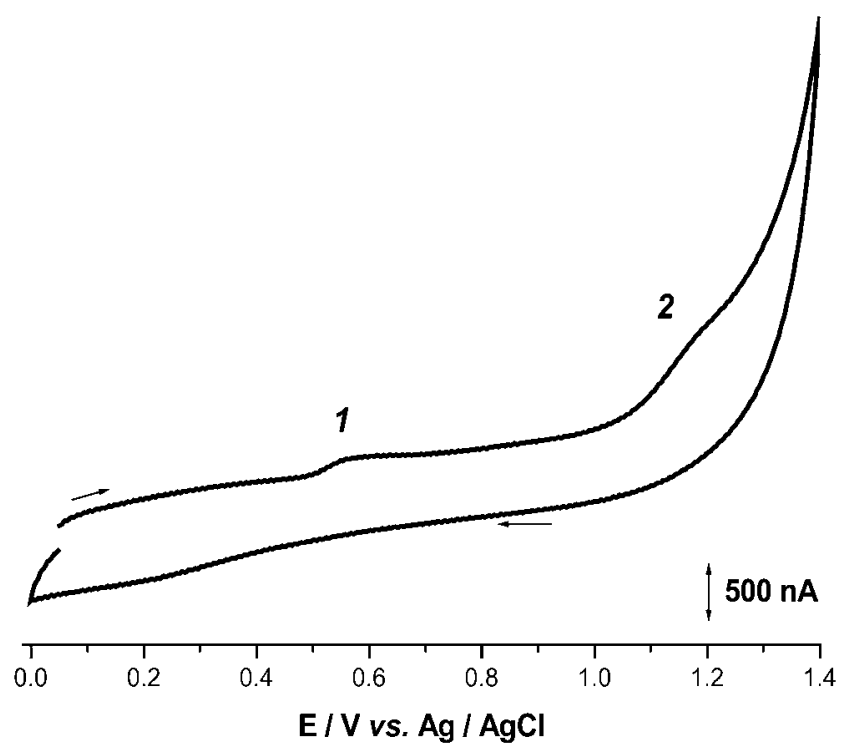

Fig. 1. Cyclic voltammograms of morin mechanically attached on the surface of $\mathrm{GCE}$ in $\mathrm{pH} 1.1 \mathrm{HCl} / \mathrm{KCl}$ buffer. Scan rate $100 \mathrm{mV} \mathrm{s}^{-1}$.

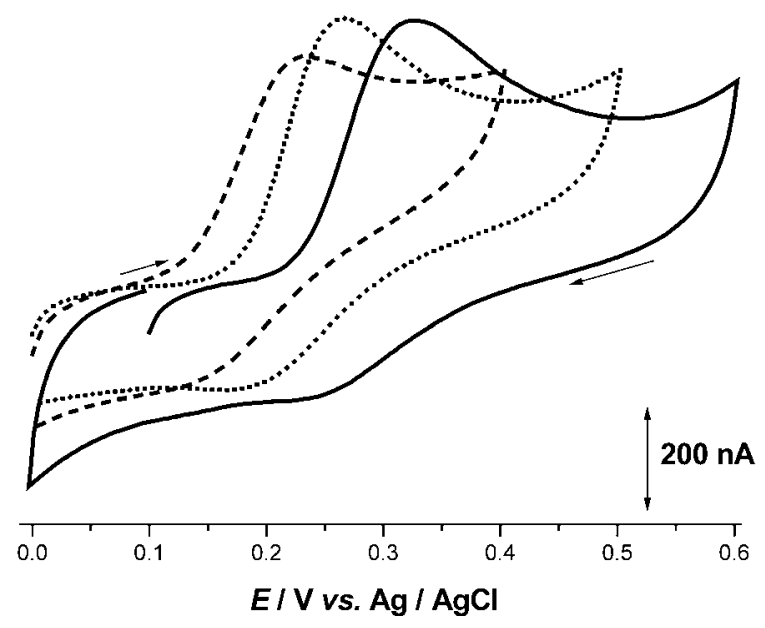

Fig. 2. Cyclic voltammograms of morin mechanically attached on the surface of GCE at different values of $\mathrm{pH}$, scan rate $50 \mathrm{mV} \mathrm{s}^{-1}:(-) \mathrm{pH} 6.0$ phosphate buffer; $(\cdots \cdots) \mathrm{pH} 7.0$ phosphate buffer; (---) pH 8.0 phosphate buffer.

which can undergo oxidation or reduction; its activity does not reside only in these groups and is enhanced by the carbonyl group, although, generally, the introduction of a carbonyl group in phenol reduces the antioxidant activity.

Cyclic voltammetry of morin hydrate at $\mathrm{pH} 1.1$ showed two oxidation peaks associated with oxidation centres in the molecule. This first is reversible peak 1 at $+0.57 \mathrm{~V}$, confirmed in the second scan by inverting the potential scan just before peak 2, and the second is the irreversible peak 2 at $+1.17 \mathrm{~V}$ (Fig. 1). The reduction peak at $+0.49 \mathrm{~V}$ corresponds to the reduction of oxidation products formed in peak 1 .

The reversibility of peak 1 was observed over the whole $\mathrm{pH}$ range studied although the separation between the

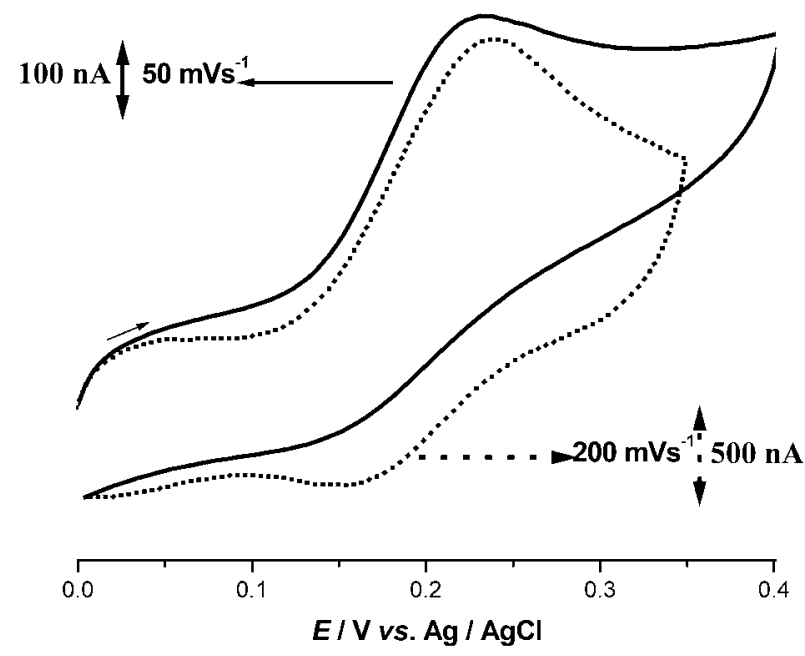

Fig. 3. Cyclic voltammograms of morin mechanically attached on the surface of GCE in $\mathrm{pH} 7.0$ phosphate buffer, scan rate: (-) $50 \mathrm{mV} \mathrm{s}^{-1}$ and $(\cdots \cdots) 200 \mathrm{mV} \mathrm{s}^{-1}$.

oxidation and the reduction peaks was smaller at $\mathrm{pH} 7.0$ (Fig. 2). Some information on the mechanism of polyphenol oxidation could be obtained by comparing the oxidation potentials at different $\mathrm{pHs}$. An increase of the solution $\mathrm{pH}$ is associated with a decrease of the oxidation potential (Fig. 2).

The oxidation products formed in the first oxidation were reversibly reduced and could also be oxidized at higher potentials. The oxidation which occurs in peak 2 was always irreversible over the $\mathrm{pH}$ range studied. Moreover, the final oxidation product blocks the electrode surface, as demonstrated by the rapid decrease of the morin oxidation peak 1 on repeated cycling. In Figure 3 are shown cyclic voltammograms of morin which illustrate that at a scan rate of $50 \mathrm{mV}$ $\mathrm{s}^{-1}$ only oxidation peak 1 is appreciable whereas at a higher scan rate, $200 \mathrm{mV} \mathrm{s}^{-1}$, reduction peak 1 is also detected. The disappearance of reduction peak 1 at low scan rates could be due to the instability of the oxidized species and/or to the very rapid formation of a non-electroactive film on the electrode surface [27]. This scan rate-dependence could also indicate an electrochemical-chemical (EC) reaction mechanism [28], consistent with a chemical rearrangement following the oxidation. The less the time allowed for the rearrangement reaction (i.e., the faster the scan rate) the more oxidation product is available to be reduced [29].

Differential pulse voltammetry (DPV) of morin was performed over a wide $\mathrm{pH}$ range from 1.1 to 9.4 (Fig. 4). Comparing the oxidation potentials at different $\mathrm{pH}$ provides information on the mechanism of morin oxidation. The strong adsorption of its oxidation product, which blocked the electrode surface, was observed, as by cyclic voltammetry since the morin oxidation peak 1 , as well as the others, decreased drastically in the second scan for all $\mathrm{pH}$ values. Peaks 1 and 2 were observed for the whole $\mathrm{pH}$ range studied.

The number of electrons transferred, $n$, was determined for peak 1 [26]. The number of protons involved in the first oxidation was then determined from the slope of the $E_{\mathrm{p}}$ vs. 
pH curve (Fig. 5). Since the relation between the oxidation potential and $\mathrm{pH}$ for peak 1 was $59 \mathrm{mV}$ per $\mathrm{pH}$ unit, it could be concluded that the first oxidation of morin corresponded to the oxidation of the $2^{\prime}, 4^{\prime}$-dihydroxy moiety at ring $\mathrm{B}$ and involved one electron and one proton.

In the plot of $E_{\mathrm{p}}$ vs. $\mathrm{pH}$ for peak 2 there is a $\mathrm{pH}$ dependent range between $\mathrm{pH} 1$ and 11; above $\mathrm{pH} 11$ the electron transfer reaction is $\mathrm{pH}$ independent. This peak should be associated with oxidation in the 5, 7-dihydroxyl moiety of ring $\mathrm{A}$, which occurs at higher potentials than oxidation due to $2^{\prime}, 4^{\prime}$-dihydroxy substituent on ring $\mathrm{B}$ or to the hydroxyl group at the C-3 position [29-31]. The plot showed that the same number of electrons and protons are involved in the second oxidation (peak 2) of morin, meaning that during the reaction both electrons and protons are removed from the

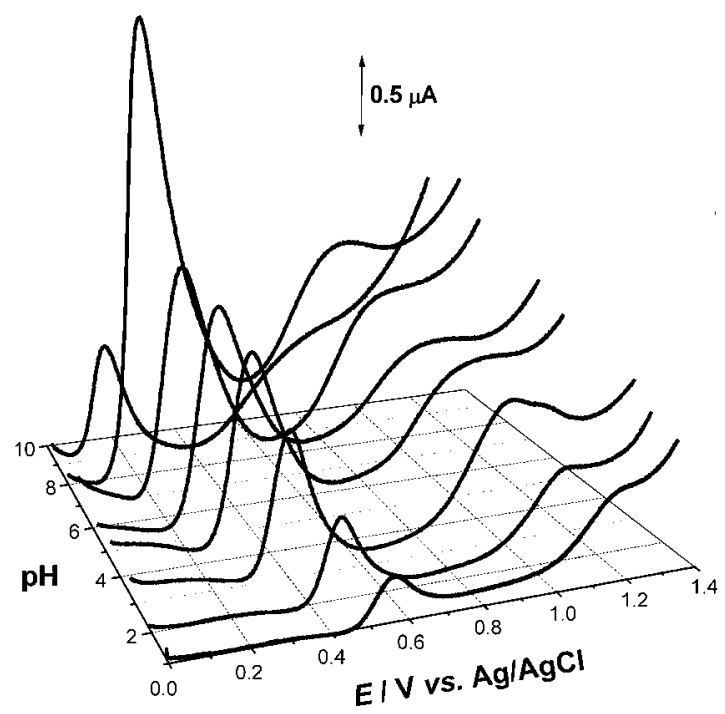

Fig. 4. 3D plot of differential pulse voltammograms of morin in buffer electrolyte as a function of $\mathrm{pH}$. Scan rate $5 \mathrm{mV} \mathrm{s}^{-1}$. molecule. The value of $W_{1 / 2}$ obtained for peak 2 was $130 \mathrm{mV}$, thus indicating that one electron is involved, and thence also one proton.

Square-wave voltammetry was also used owing to its greater speed of analysis, lower consumption of electroactive species in relation to differential pulse voltammetry, and reduced problems with blocking of the electrode surface [26, 32].

Similar results to differential pulse and cyclic voltammetry were obtained, i.e., oxidation peaks 1 and 2 , the appearance of significantly lower currents due to adsorption on the second scan, together with a decrease in peak current in more acidic and in more alkaline media. The square-wave voltammetry conditions chosen, an effective scan rate of $50 \mathrm{mV} \mathrm{s}^{-1}$, led to well-defined voltammograms, Figures 6 and 7. A great advantage of the square-wave method is the possibility to see during one scan if the electron transfer reaction is reversible or not. Since the current is sampled in both the positive and the negative-going pulses, peaks corresponding to the oxidation or reduction of the electroactive species at the electrode surface are obtained in the same experiment. The reversibility of the oxidation peaks 1 of morin is clearly shown for all pHs studied, Figures 6 and 7 , where the forward and backward currents are similar and the oxidation and reduction peaks occur at the same potential. The second oxidation reaction in morin always showed irreversibility. These results compare very well with those from cyclic and differential pulse voltammetry.

The electrochemical properties of solid materials such as organic compounds, irrespective of their electrical conductivity, can be studied via the use of submicron sized particles mechanically attached to electrode surfaces immersed in aqueous media containing different electrolytes [33].

Morin presents conjugation between rings $\mathrm{A}$ and $\mathrm{B}$. It has different pharmacophores, the moiety group in ring-B and the three hydroxyl groups in rings $\mathrm{A}$ and $\mathrm{C}$. The activity of the $3 \mathrm{OH}$ groups is enhanced by an electron donating effect

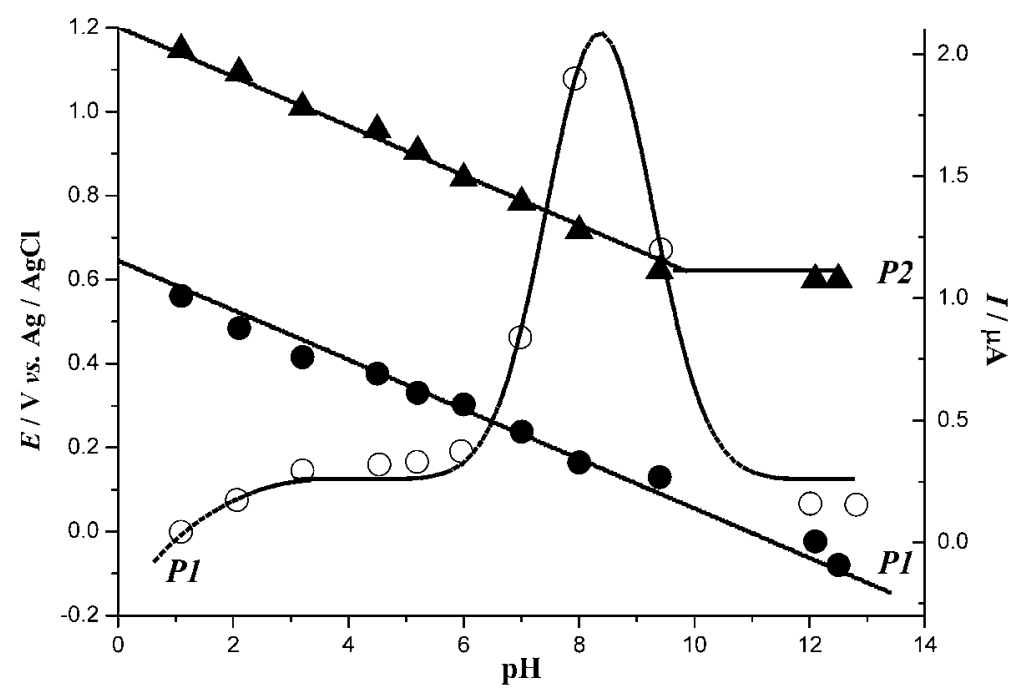

Fig. 5. Dependence of differential pulse parameters of morin on pH in buffer supporting electrolyte: (○) $I_{\mathrm{p}}$ of peak $1 ; E_{\mathrm{p}}$ of $(\bullet)$ peak 1 and $(\mathbf{\Lambda})$ peak 2. 


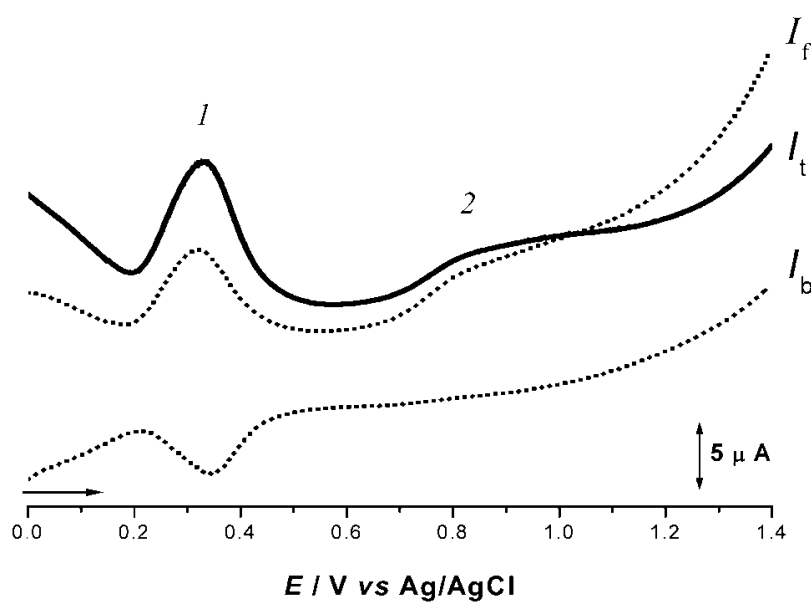

Fig. 6. Square-wave voltammogram of morin mechanically attached on the surface of GCE in pH 6.0 phosphate buffer: $I_{\mathrm{t}}$ : total current, $I_{f}$ : forward current and $I_{b}$ : backward current. Frequency $50 \mathrm{~Hz}$, effective scan rate $100 \mathrm{mV} \mathrm{s}^{-1}$. of the hydroxyl groups at positions 5 and 7. The hydroxyl groups in ring $\mathrm{B}$ are electron-donating and stabilize active intermediates, and the C-3 hydroxyl group can also form intermolecular hydrogen bonds with the oxygen at C-4, also stabilizing active intermediates.

Morin oxidation proceed in a cascade mechanism related with the substituent group in ring B and the resorcinol group in ring A which all present electroactivity, and the oxidation potentials are identified with peaks 1 and 2, described above.

The oxidation of the ring $\mathrm{B}$ moiety, $2^{\prime}, 4^{\prime}$-dihydroxyl electron-donating groups at ring $\mathrm{B}$, occurs first at very low positive potentials corresponding to peak 1 , and is one electron one proton reversible reaction as described. The hydroxyl group at position 3 at ring $\mathrm{C}$ should be oxidized afterwards. However, it was not observed because this hydroxyl group can also form a intermolecular hydrogen bond with the oxygen at position 4 at ring-C [24]. The hydroxyl groups at positions 5 and 7 at ring A also have an electron donating effect and the oxidation is irreversible, as

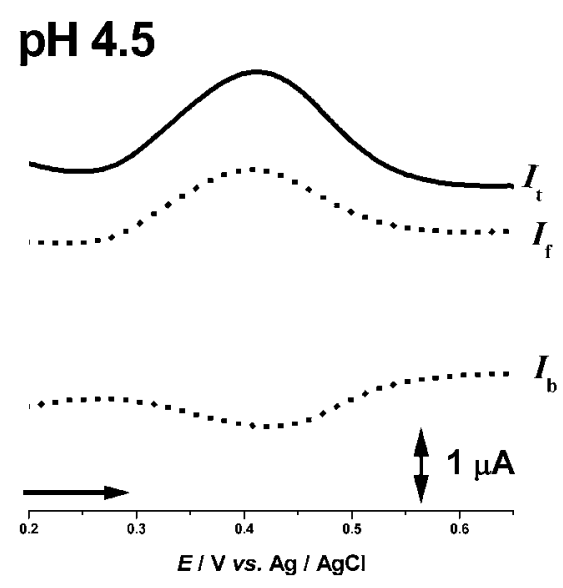

pH 8.0
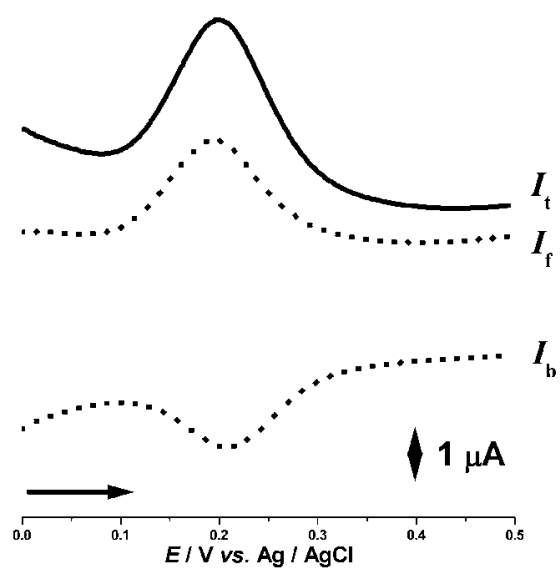

pH 7.0

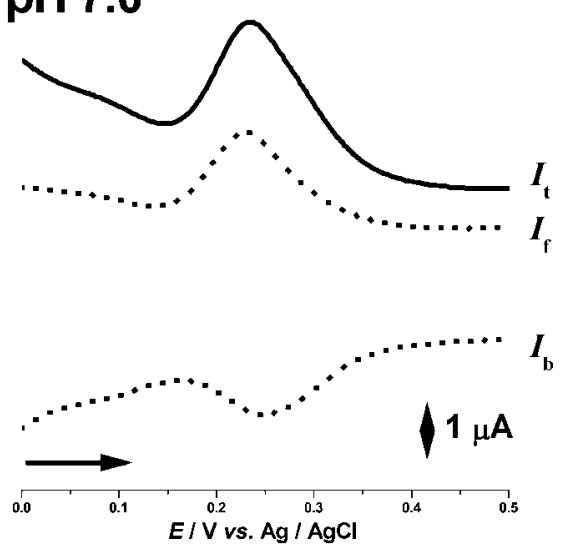

pH 12.0
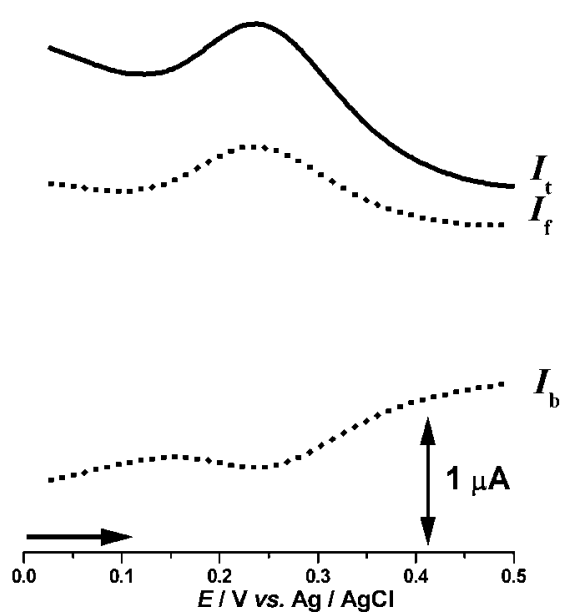

Fig. 7. Square-wave voltammogram of morin mechanically attached on the surface of GCE at different pH. Frequency $25 \mathrm{~Hz}$, amplitude $50 \mathrm{mV}$, effective scan rate $50 \mathrm{mV} \mathrm{s}^{-1}$. 
shown by square-wave voltammetry, and occurs for higher positive potentials, corresponding to peak 2 .

The current of peak 1 is very high compared with the current of peak 2, which is in agreement with the higher radical scavenging activity associated with the oxidation of the ring $\mathrm{B}$ moiety. The oxidation current is higher at $\mathrm{pH}$ values corresponding to hydroxyl deprotonation, meaning that after deprotonation the electron transfer becomes easier, and the mechanism of radical scavenging antioxidant activity of morin in the neutral form is increased.

\section{Conclusions}

This oxidation process of morin is complex, $\mathrm{pH}$-dependent and the first step is reversible. Morin is strongly mechanically attached on the electrode surface. The first electron transfer reaction of morin is reversible over the whole $\mathrm{pH}$ range, and a dependence of peak current on $\mathrm{pH}$ was observed showing a maximum at $\mathrm{pH} 8$. The influence of the deprotonation of the ring $\mathrm{B}$ moiety group is related to the electron/proton donating capacity of morin and to its radical scavenging antioxidant activity. The data obtained are consistent with available knowledge and suggest that voltammetric studies on mechanically transferred solids may provide a convenient method for studying the electrochemical oxidation mechanisms of this type of compound in aqueous media.

\section{Acknowledgements}

Financial support from Fundação para a Ciência e Tecnologia (FCT), POCTI (cofinanced by the European Community Fund FEDER), ICEMS (Research Unit 103) and European Projects QLK3-2000-01311 and HPRN-CT-200200186 are gratefully acknowledged.

\section{References}

[1] C. A. Rice-Evans, N. J. Miller, G. Paganga, Trends Plant Sci. 1997, 2, 152.

[2] R. A. Larson, Phytochemistry 1988, 27, 969.

[3] J. B. Harborne, C. A. Williams, Phytochemistry 2000, 55, 481.

[4] H. Hotta, S. Nagano, M. Ueda, Y. Tsujino, J. Koyama, T. Osakai, Biochim. Biophys. Acta 2002, 1572, 123.
[5] C. A. Rice-Evans, N. J. Miller, G. Paganga, Free Radical Biol. Med. 1996, 20, 933.

[6] C. G. M. Heijnen, G. R. M. M. Haenen, J. A. J. M. Vekemans, A. Bast., Environ. Toxicol. Pharmacol. 2001, 10, 199.

[7] B. Yang, A. Kotani, K. Arai, F. Kusu, Anal. Sci. 2001, 17, 599.

[8] H. Hotta, H. Sakamoto, S. Nagano, T. Osakai, Y. Tsujino, Biochim. Biophys. Acta 2001, 1526, 159.

[9] T. E. Keyes, R. J. Foster, A. M. Bond, W. Miao, J. Am. Chem. Soc. 2001, 123, 2877.

[10] A. M. Bond, J. Solid State Electrochem. 1997, 1, 185.

[11] T. Grygar, F. Marken, U. Schröder, F. Scholz, Collect. Czech. Chem. Commun. 2002, 67, 163.

[12] F. Scholz, B. Meyer, Chem. Soc. Rev. 1994, 23, 341.

[13] N. F. Zakharchuk, B. Meyer, H. Henning, F. Scholz, A. Jaworksi, Z. Stojek, J Electroanal Chem. 1995, 398, 23.

[14] P. Bezdicka, T. Grygar, B. Klapste, J. Vondrak, Electrochim. Acta 1999, 45, 913.

[15] S. Komorsky-Lovric, V. Mirceski, F. Scholz, Mikrochim. Acta 1999, 132, 67.

[16] S. Komorsky-Lovric, I. Galic, R. Penovski, Electroanalysis 1999, 11, 120.

[17] S. Komorsky-Lovric, N. Vukasinovic, R. Penovski, Electroanalysis 2003, 15, 544.

[18] S. Komorsky-Lovric, J. Solid State Electrochem. 1997, 1, 94.

[19] P. Zuman, J. J. M. Holthuis, Recueil des Travaux Chimiques des Pays-Bas 1988, 107, 403.

[20] L. D. S. Kok, Y. P. Wong, T. W. Wu, H. C. Chan, T. T. Kwok, K. P. Fung, Life Sci. 2000, 67, 91.

[21] S. V. Jovanovic, S. Steenken, Y. Hara, M. G. Simic, J. Chem. Soc. Perkin Trans. 1996, 2, 2497.

[22] C. Cren-Olivé, P. Hapiot, J. Pinson, C. Rolando, J. Am. Chem. Soc. 2002, 124, 14027.

[23] S. V. Jovanovic, S. Steenken, M. Tosic, B. Marjanovic, M. G. Simic, J. Am. Chem. Soc. 1994, 116, 4846.

[24] N. P. Slabbert, Tetrahedron 1977, 33, 821.

[25] S. Steenken, P. Neta, J. Phys. Chem. 1982, 86, 3661.

[26] C. M. A. Brett, A. M. Oliveira Brett, Electrochemistry: Principles, Methods and Applications, Oxford Science Publications, Oxford 1993.

[27] W. F. Hodnick, E. B. Milosavijevic, J. H. Nelson, R. S. Pardini, Biochem. Pharmacology 1988, 37, 2607.

[28] B. Yang, K. Arai, F. Kusu, Anal. Sci. 2001, 17, 987.

[29] H. P. Hendrickson, A. D. Kaufman, C. E. Lunte, J. Pharm. Biomed. Anal. 1994, 12, 325.

[30] M. Filipiak, Anal. Sci. 2001, 17, 667.

[31] A. M. Oliveira Brett, M. E. Ghica, Electroanalysis 2003, 15, 1745.

[32] C. M. A. Brett, A. M. Oliveira Brett, Electroanalysis, Oxford Science Publications, Oxford 1998.

[33] A. M. Bond, F. Marken, E. Hill, R. G. Compton, H. Hügel, J. Chem. Soc. Perkin Trans. 1997, 2, 1735. 